\title{
Informed consent and the psychiatric patient
}

\author{
Allen R Dyer and Sidney Bloch Duke University Medical Center, Durham, North Carolina, \\ and Warneford Hospital, Oxford respectively
}

\section{Authors' abstract \\ Informed consent is reviewed as it applies to psychiatric patients. Although new legislation, such as the Mental Health Act 1983, provides a useful safeguard for the protection of the civil rights of patients, it could actually reduce their humane care unless applied with sensitivity for the nature of their unique difficulties. In order to guard against this possibility, we suggest that legal requirements should be considered in light of the ethical principles which underlie them. Three principles are considered: those of autonomy (freedom); beneficence (paternalism); and the fiduciary principle (partnership). Psychotherapy is offered as a model for informed consent, which might be generalised to other clinical situations.}

The central importance of informed consent in psychiatric practice and the emphasis on the protection of patients' civil liberties in the new Mental Health Act 1983 occasion a review of informed consent and the ethical principles on which it is based. Likely to set the legal standard into the 21st century, the Mental Health Act 1983 takes a constructive step towards the statutory resolution of many of the ambiguities in the relationship between psychiatrists and patients. Moreover, the Act represents a safeguard of the rights of psychiatric patients. But there is a serious risk that its rigid and uncaring application may paradoxically have a dehumanising effect. As Bloch and Chodoff (1) have noted:

'The impact of the civil liberties movement has been favourable to the development of a socially responsible ethical sense. However, it is possible that one effect of so intense a legal involvement in psychiatric issues may have been counterproductive. To attempt to specify every aspect of the professional relationship in contractual terms leaves little room for the exercise of individual ethical judgment, and indeed may discourage its exercise. It has been observed that: "in hell there will be nothing but law and due process will be meticulously observed".'

\section{Key words}

Informed consent; informed consent and the psychiatric patient; Mental Health Act 1983.
In this paper we examine the concept of informed consent and how it is applied to psychiatric patients. We argue that the best balance of a sensitive and humane application of the legal requirements governing informed consent may be effected by appreciating the ethical principles which underlie these requirements. First, however, we need to consider the concept of informed consent generally and its application in psychiatric practice.

\section{The concept of informed consent}

The concept of informed consent was first discussed in the early 20th century, in relation to surgery. In order to conduct an operation, the patient was required to consent. The laws governing this in both England and the United States are the laws of battery. Informed consent was first applied to medical experimentation during the Nuremberg Trials in 1947. Current standards were set forth in the Declaration of Helsinki in 1965. The application of informed consent to psychiatric treatment has been given increasing attention in the legal and ethical literature of the past two decades, resulting in 'liberalisation' of the mental health laws of most Western countries (2). Such legislation usually entails a form of due process review for involuntary psychiatric hospitalisation and may also specify review for other procedures. An example of the latter is the stipulation in the Mental Health Act 1983 , which requires that consent and a second opinion must be obtained for (a) any surgical procedure for a mental disorder which destroys brain tissue or (b) the surgical implantation of hormones to reduce male sexual drive; and consent or a second opinion for (a) electro-convulsive treatment or (b) medication (during detention of a patient for treatment of a mental disorder) for over three months (3).

Informed consent is usually considered to be the process whereby explicit communication of information is provided, which would be relevant for a patient or experimental subject to decide whether or not to have a particular treatment or to participate in a particular experiment. In fact consent has three components: it must be (a) informed, (b) voluntary, and (c) competent. Apart from the communication of information, it also involves the act of consenting. 
'Consent' derives from the Latin com- + sentire to feel, hence to feel together. It means 'agree', 'assent', or 'give permission' and indicates involvement of the will or feelings and compliance with what is requested or desired. Implicit in the definition is a community of feeling, a shared trust which goes beyond a mere explicit contractual arrangement. Recognising this mutuality, Guttentag (4) offers a useful definition of informed consent in research settings, but which may also be applicable as a matter of ethical principle though not legal requirement to clinical practice:

'Informed consent may be defined as the experimenter's willing obligation to inform the experimental subject, to the best of the experimenter's knowledge, about the personal risk that the experimental subject faces in the proposed experiment, the significance of the experiment for the advancement of knowledge and human welfare, and last but not least, the stakes involved for the experimenter himself. In short, informed consent implies that the experimenter has made the most honest effort he can to say everything that will enhance the experimental subject's freedom, so that the subject can make the most adequate choice of which he is capable in agreeing or refusing to become a volunteer.'

\section{The problem of paternalism}

In clinical practice, as in research, the individual's autonomy or freedom is fundamental to the exercise of a genuinely informed consent. In psychiatric practice, particularly, this autonomy may be limited since the patient's clinical state may make him unable to exercise free judgement or it may interfere with thought processes required to comprehend the nature of the treatment proposed. In these situations it is usual for professionals to act paternalistically on the person's behalf. It is also common to involve a third party as an overseer of the process of informed consent in order to safeguard against abuse. The more the profession is perceived as needing to act paternalistically, the more it is felt that a form of overseeing, such as that enacted in the Mental Health Act 1983, is appropriate.

But, there is an irony in such protective safeguards. Transferring the paternalistic role from the psychiatrist to a third party, such as a Mental Health Act Commissioner or other patient' advocate, does not restore the autonomy of the patient. It merely substitutes someone else as a spokesman for the patient. While the goal of protecting the patient is laudable, the effect may not be so.

Stanley and Stanley (5) have highlighted the negative consequences of a protective attitude towards psychiatric patients. One major effect is paradoxically a loss of autonomy: the decisions as to whether to select a certain treatment or participate in certain research are taken out of their hands. Furthermore, the mentally ill are labelled as different from others, specifically as more vulnerable, and therefore less capable of appraising situations with regard to their self-interest.
This arbitrary portrayal of a highly heterogeneous $\underset{=}{ \pm}$ clinical population may inadvertently give tacit $\overline{\bar{\delta}}$ approval to society to discriminate against psychiatric $\stackrel{\Rightarrow}{\Rightarrow}$ patients. In an effort to protect them, another stigma is $\stackrel{\bar{c}}{?}$ added to their being classified as mentally ill. The $\bar{C}$ implication of requiring special protection is that psychiatric patients are incapable of functioning as $\frac{\overline{\bar{\rho}}}{\frac{}{5}}$ autonomous persons. Finally, a protective policy may $\underset{\complement}{\Phi}$ have the unintended effect of infantilising patients by depriving them of some of their decision-making $\rightarrow$ power. This may contribute to the lowering of self-. esteem and foster unnecessary dependency. $\vec{\omega}$ Protectiveness is a double-edged sword. While it must $\stackrel{\omega}{\stackrel{S}{S}}$ be recognised that there are good reasons for $\overline{3}$ safeguards, the therapeutic goal of increased autonomy must be kept in mind in applying the safeguards, lest $\vec{\omega}$ protectiveness work against the best interests of the $\overrightarrow{\overrightarrow{.}}$ patient.

\section{Ethical theory and the law}

The problems which arise in stipulating legalo safeguards of the civil rights of psychiatric patients $\stackrel{\bigcirc}{\sim}$ stem from the ambiguous relationship between the law $\overrightarrow{0}$ and ethical theory. Inevitably the law must be specifico on points about which ethical theory might be more general. The risk of such specificity is that the besto interests of an individual patient may not be met by procedures designed to protect the psychiatrico population as a whole.

In this context, a cultural conflict - highly relevant $\stackrel{\mathbb{Q}}{\mathcal{Q}}$ to informed consent - contrasts two perspectives of $\overrightarrow{0}$ human beings and their relationships to one another. 3 On the one hand the person is regarded as autonomous; on the other hand paternalism is recognised in the? declaration of the non-autonomous person as in need of protection. The conflict is created by uncertainties about the extent to which the individual's - and society's - well-being is better served by encouraging self-determination or supporting paternalism.

Whereas paternalism might formerly have been taken as a measure of the doctor's responsibility for his윽 patient, it might equally well be seen today as a measure of professional control in an impersonal medical setting.

Increasingly, we seem to be moving away from broad and general ethical principles that have evolved over centuries toward a civilly-enforced body of lawe and administrative regulations. The sociologist Toennies (6) has interpreted this as a shift fromo Gemeinschaft (a community of feeling that results from $\$$ likeness and shared life experience) to Gesellschaft (a society based on more impersonal structures with explicit rules and regulations). Ethics in a Gesellschaft becomes a formal exercise. There is an attempt to

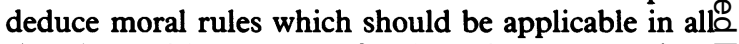
situations without regard for the unique needs of the persons involved. Thus for psychiatry the law serves aso a useful reminder of important ethical principles, buto at the same time may fail to safeguard the optimalstandard of individualised clinical care which 
characterises medical ethics at its best.

The Mental Health Act 1983 exemplifies the Gemeinschaft/Gesellschaft issue. At its best the Act can serve patients by providing a mechanism to protect their civil rights. The Act can aid the profession too, by reducing unnecessary suspiciousness and distrust among the vulnerable population of psychiatric patients. These benefits depend on a sensitive and caring application of its stipulations.

At its worst the Act involves an overseer in the doctor-patient relationship who may:

(1) Humiliate patients through a public review of their difficulties.

(2) Make the therapeutic alliance difficult or impossible to achieve.

(3) Deprive patients of potentially beneficial treatment.

(4) Add time-consuming, administrative tasks for the psychiatrist to perform.

These sorts of difficulties are exemplified in a report from the Geoffrey Knight Psychosurgical Unit at the Brook Hospital in London. Bridges (7) cites problems that the unit has encountered with the Mental Health Act Commission under the provisions of the Mental Health Act 1983 involving psychosurgery, problems 'that seem to be more to do with its policies than the Act itself. He notes that the commission have tended to be 'aloof and adversarial'. Although the unit's staff have welcomed help in dealing with the question of informed consent, they have found that the commission in their required role of issuing a second opinion have not limited their role to the review of the consent process and advising the patient, but have actually gone to the length of preventing one patient from having the operation. This illustrates the problem of a patient being deprived of the right to consent because the decision conflicts with another person's judgement about what was in the patient's best interests. Bridges raises the question of the control of medical practice by lay persons, and by those who are not involved in actual clinical care, and who bear no direct clinical responsibility for, or accountability to, the patient.

Alongside the problem of the complicated relationship between the law and ethical theory because of the requirement of the law to be highly specific, is another factor which reflects paradoxically the inability of the law always to be specific. In certain circumstances, the law is framed in such a way as to make it liable to different interpretations. One such circumstance is the patient's need for relevant information before consenting to treatment. What constitutes relevant information? Can the law specify this? In some of the United States, the law has stipulated that consent can be regarded as informed only when the 'prudent patient' test is satisfied, that is the 'reasonable' patient is told about all material risk involved in the proposed treatment to which he or she would probably attach significance in coming to a decision whether or not to forego the proposed treatment (8).

Recently, English law has adopted a quite different position. In Sidaway v Bethlem Royal Hospital (9), the plaintiff brought an action in negligence on the grounds that her surgeon had been in breach of his duty because he had failed to warn her of all the possible risks inherent in the operation she underwent; she had therefore not been in a position to give informed consent to the treatment. The question dealt with in the Sidaway case was how much information a doctor is required to convey to a patient. It was determined in the Court of Appeal that a doctor was under a general duty to disclose such information as was reasonable to enable the patient to make a rational choice whether to agree or refuse a proposed treatment, but that the doctrine of informed consent, based on full disclosure of all the risks inherent in the treatment, was not the appropriate test in English law. The doctor was discharging his duty reasonably if he acted in accordance with clinical practice 'rightly accepted by a body of skilled and experienced medical men' (p 1018).

Some of the reasoning underlying this judgement is embodied in the following conclusion:

'The evidence in this case showed that a contrary result would be damaging to the relationship of trust and confidence between doctor and patient, and might well have an adverse effect on the practice of medicine. It is doubtful whether it would be of any significant benefit to patients, most of whom prefer to put themselves unreservedly in the hand of their doctors. This is not in my view "paternalism", to repeat an evocative word used in argument. It is simply an acceptance of the doctor/patient relationship as it has developed in this country. The principal effect of accepting the proposition advanced by the plaintiff would be likely to be an increase in the number of claims for professional negligence against doctors. This would be likely to have an adverse effect on the general standards of medical care, since doctors would inevitably be concerned to safeguard themselves against such claims, rather than to concentrate on their primary duty of treating their patients' (pp 1030-1031).

Although the House of Lords upheld the decision of the Court of Appeal (10), it is of interest that Lord Scarman did dissent and argued that the doctor was obliged to consider the right of the patient to make up her own mind in the light of 'material (relevant) information'. This is not the place to delve further into the crucial and complex issues generated by the Sidaway case. Suffice to say, we note the significance attached to the nature of the doctor-patient relationship, including factors such as a trust in, and dependency on, the doctor to promote the patient's best interests. Although paternalism is denied, it is evident that some form of paternalistic action is 
invoked by the judgement. Is such a position ethically justified? Can the therapeutic relationship be construed in terms other than paternalistic? We now turn to the relationship between informed consent and ethical theory in order to consider these and related questions.

\section{Informed consent and ethical theory}

The example of the patient denied psychosurgery, coupled with the Sidaway case, reflect the complexity of the process of consent, and also demonstrate that the dilemma between respect for a patient's autonomy and the need for some degree of paternalism is inescapable. Regulatory guidelines as set forth in such statutes as the Mental Health Act 1983 are undoubtedly necessary to safeguard the patient's interests but are not sufficient to ensure the highest ethical standards towards which a psychiatrist should aspire. One way in which the psychiatrist can pursue these standards is through close familiarity with and an appreciation of the ethical principles which underlie the legal requirements. To this end three competing ethical principles - those of autonomy (freedom), beneficence (paternalism), and the fiduciary (partnership) - are briefly considered. This will in turn pave the way for our suggestion that psychotherapy can serve as a prototype for the relationship which is necessary for the optimal process of informed consent.

Current philosophical justification for informed consent is held to rest on the principle of autonomy (11), namely that a person has basic human rights, including the right to self-determination. An immediate difficulty arises: if we assert that informed consent is required because people are autonomous, then we are left at an impasse at how to treat the person whose autonomy is limited; for example, the acutely psychotic patient, the demented, the child and the subject of research involving deception. One solution of declaring such a person as incompetent - that is lacking the capacity to act in his own best interests and hence in need of guardianship or proxy consent places us back in the bind of paternalism. The issue of informed consent in such situations then depends on an assessment of the competence of the person in question.

Ethical traditions as old as that of Hippocrates stress not only the avoidance of harm to the patient (nonmaleficence), but also the provision of some benefit (beneficence): 'I will use treatment to help the sick, but I will never use it to injure or wrong them' (12). The principle of beneficence figures heavily in utilitarian theory in which there are calculations of the relative good (utility) and trade-offs of cost and benefit. The question of paternalism arises in so far as a judgement about potential benefit must be made; the possibility of conflict arises if the judgements of the psychiatrist and patient are not in accord. Thus the principles of paternalistic beneficence and autonomy may conflict.

The fiduciary principle (partnership) is a third possibility upon which the requirement of informed consent may be based. The doctor-patient relationship is often referred to as a relationship of trust. The $\underset{+}{=}$ patient trusts the doctor, the ethics of whose profession $\bar{\varnothing}$. are oriented toward promoting trust (through such $\Rightarrow$ requirements as maintaining confidentiality and $\stackrel{D}{\rightarrow}$ setting professional standards). An important aspect of $O$ the therapeutic relationship may depend on the patient trusting the doctor sufficiently to disclose relevant $\frac{\overline{\bar{s}}}{\overline{5}}$ personal details of history and symptoms; trusting that $\stackrel{\Phi}{\Phi}$ the doctor will always act on the patient's behalf; and trusting that the doctor is competent.

We argue that the fiduciary principle offers $a \cdot \vec{\circ}$ resolution to the conflict between the principles of $\vec{\omega}$ autonomy and paternalistic beneficience with regard to $\stackrel{\omega}{S}$ consent. Unlike the legal use of the term fiduciary $\overline{\overline{3}}$ where a trustee decides for the client and acts on his behalf, in medicine the doctor decides with the patient, $\vec{\omega}$ a process dependent on the development of the latter's.. trust (13). Although the fiduciary principle in $\vec{N}$ medicine is a two-way street, requiring mutual trust, it 음 particularly calls on the doctor to be trustworthy. The principle is best conceptualised as a form of partnership. Guttentag (4) captures its essence when he suggests that partnership is the most fundamental ethical aspect involved in informed consent.

'With reference to the relationship between (doctor' and patient), it is the concept of partnership between the two, resulting from the fact of their being fellow human beings, that reflects our basic belief and cannot be subordinated to any other.'

By partnership Guttentag does not imply a legal $\vec{\circ}$ contract, but 'sincerity without reserve, a relationship 3 of mutual trust and confidence, or openness . . . that discards any guardedness'. A criterion of thiș partnership is the personal effort involved in its. enactment, "the amount of "loving care", or devotion given to disclosing the content and limits of any actualo partnership. It is the antipode to negligence'.

The notion of partnership is a reminder thato important personal qualities are involved in the pursuit and maintenance of the highest ethical standards. Furthermore, deployment of such terms as 'trust' 'sincerity', and 'loving care' emphasises a dimension of. ethical responsibility that is omitted in the modern ethical vocabulary of minimalist operationa? guidelines.

The principle of partnership represents the ethicat ideal even more fundamentally than the paternalism of which the medical profession is often accused, or theo more impersonal respect for autonomy which is, commonly substituted for it.

Psychotherapy as a model for informed consent

Recognition of the dimension of time helps to resolve the conflict posed by rival ethical theories for the problem of informed consent. The juxtaposition of autonomy and paternalism, seen as mutually exclusive principles, is unfortunate and misleading. Whereas paternalism might have formerly been regarded as a manifestation of the doctor's responsibility, it is now? 
often construed as a measure of his professional control over the patient. By acting paternalistically, the doctor is limiting the patient's autonomy. On the other hand the autonomous patient is regarded as not needing to be dependent on the doctor. What is missing from this analysis is the dimension of time. The static formulations of the doctor as paternalistic or of the patient as autonomous are characterisations that may reflect a given situation at a particular moment, but say nothing about their relationship over time.

The task of the therapist in psychotherapy offers a prototype of the partnership which, in our view, is a requisite for genuine informed consent. In psychotherapy, the establishment of a trusting alliance between therapist and patient is a primary objective from the outset and one which endures as a basis for all subsequent work. The alliance provides a model for the process of informed consent in other clinical contexts in psychiatry. The two partners have one overriding goal in their collaboration: to understand and clarify the motives of the patient. The ambiguities of communication are taken with utmost seriousness. The partners recognise that the communication between them may have many levels of meaning, conscious and unconscious and that not all these levels can be appreciated simultaneously. Informed consent occurs not once, but repeatedly, as therapist and patient work together to bring into the latter's conscious awareness that which has hitherto been unknown or obscure.

Viewing informed consent as a continuing process which occurs within the framework of a fiduciary relationship enhances in the therapist a particular sense of responsibility. He attempts to identify the specific needs of his patient and to respond to them. Recognising for example that dependency may be intrinsic to the therapeutic relationship, he may act paternalistically. Such paternalism may reflect a concern for the patient comparable to that shown by a responsible parent for its child. Only in indifference does one treat a child or a dependent patient as completely autonomous. Although autonomy is regarded as a goal of the therapeutic encounter, it is not in itself the exclusive basis for the psychotherapist's ethical concern for this patient.

\section{Conclusion}

Informed consent is a fundamental safeguard of the rights of the psychiatric patient. But it occupies a muddled position in both legal and ethical theory. The ethical principles on which informed consent is based need to be carefully considered, lest a rigid and insensitive application of legal requirements actually works to the patient's detriment. The principle of autonomy is central in informed consent, yet it does not cover adequately the situation of the patient whose autonomy may be restricted. More fundamental is the principle of partnership with its emphasis on the psychiatrist's trustworthiness.

Not only patients but also the psychiatric profession should be served by legislation which clarifies the rights of patients. However, this appreciation of the utility of the law should be tempered by two notes of caution. First, for psychiatrists: the principle of partnership should be respected because even prior to any legal statute, it is a fundamental aspect of good ethical practice. Secondly, third party overseers, who may not be bound by the same traditions of medical ethics, should temper their judgements, not only by considering what might be best for patients, but also by a diligent attempt to get to know and to understand the patients themselves in order to ensure that their interests and needs are respected in a sensitive and caring way.

Allen $R$ Dyer, $M D, P h D$, is Associate Professor, Department of Psychiatry, Duke University Medical Center, Durham, North Carolina. Sidney Bloch, MB, PhD, FRCPsych is Consultant Psychiatrist, Warneford Hospital, Oxford and Clinical Lecturer, Department of Psychiatry, University of Oxford.

\section{References}

(1) Bloch S, Chodoff P. Introduction. In: Bloch S, Chodoff P, eds. Psychiatric ethics. Oxford: Oxford University Press, 1981.

(2) Whitehead T. Mental illness and the law Oxford: Basil Blackwell, 1983.

(3) Bluglass R. A guide to the Mental Health Act 1983. Edinburgh: Churchill Livingstone, 1984.

(4) Guttentag O. Ethical problems in human experimentation. In: Torrey E F, ed. Ethical issues in medicine. Boston: Little, Brown, 1968.

(5) Stanley B, Stanley M. Psychiatric patients in research: protecting their autonomy. Comprehensive psychiatry, $1981 ; 22: 420-427$.

(6) Toennies F. Fundamental concepts of sociology. New York: American Book Co, 1940.

(7) Bridges P. Psychosurgery and the Mental Health Act Commission. Bulletin of the Royal College of Psychiatrists 1984; 8:146-148.

(8) Canterbury $v$ Spence (1972) 464 F 2d 722.

(9) Sidaway $v$ Bethlem Royal Hospital Governors and Others. 1. All England Law Reports. 1984, 1018-1036.

(10) Sidaway $v$ Bethlem Royal Hospital Governors. 1. All England Law Report. 1985, 643 (HL).

(11) Veatch R. Three theories of informed consent: philosophical foundations and policy implications. In: The Belmont Report: Ethical principles and guidelines for the protection of human subjects of research. Washington DC: DHEW publication No (OS) 78-0014, 1978.

(12) Beauchamp T, Childress J. Principles of biomedical ethics. New York: Oxford University Press, 1979.

(13) This distinction is especially relevant in the light of the rejection by Dunn L J in the Sidaway case (9) of the concept of doctors owing more than a duty of care to their patients and standing in a fiduciary relationship to them (see page 1029e). 